\section{Environmental inspection agro tech - guarantee sustainable development agricultural systems}

\author{
Makarenko, Natalia ${ }^{1}$ - Bondar, Valeria ${ }^{1}-$ \\ Makarenko, Volodymur ${ }^{2}$ \\ ${ }^{1}$ National University of Life and Environmental Sciences of \\ Ukraine, Kyiv, Ukraine \\ ${ }^{2}$ Taras Shevchenko National University of Kyiv, Kyiv, Ukraine \\ n-mak@ukr.net
}

\section{SUMMARY}

Shown the expediency of the environmental expertise technologies of growing crops in terms of impact on soil fertility, crop phytosanitary status, quality, chemicals migration, biological soil activity, crop productivity, which ensure avoidance of adverse impact on the environment and human health.

Keywords: environmental impact assessment, hazard factors, agriculture, environmental safety, environmental protection

One reason for the deterioration of natural resources, agro-ecosystems is the use of imperfect technologies of growing crops or violation of certain processes.

At the present stage of social development should timely to avoid possible negative effects of certain economic activities except of the monitor and statement facts of the environmental degradation due to human activities. In the crop growing this can be achieved only if the preventive technologies evaluation of growing crops, which may decrease soil fertility, deterioration of product quality, water pollution, disappearance of useful species of flora and fauna.

Preliminary expertise of crop production technologies, including their environmental expertise is expedient to carry out under development and testing before widespread introduction into production. This will avoid a negative impact on the environment and human health, and will assess the environmental safety technologies available to agricultural producers.

The basic principles of environmental expertise technologies of growing crops should to be ensure a safe and health environment, balancing environmental, economic, biomedical and social interests, scientific validity, preventive methods.

In the world practice to prevent the negative impact of technology on the environment and quality apply the HACCP system (Hazard Analysis and Critical Control Points), which provides a more structured and scientific approach to the hazard factors control than traditional procedures for quality control of final product (Law of Ukraine "On Ecological Expertise", 1995).

In Ukraine, environmental expertise technologies of agricultural production is expedient according to the Laws "Ecological Expertise", "Pesticides and Agrochemicals", which include determining the degree of environmental risk and safety planned or ongoing activities; organization of comprehensive, science-based expertise objects of environmental review; mapping objects expertise requirements environmental legislation, health standards; Expertise of sites of ecological expertise the state of the environment, health and quality of natural resources (Law of Ukraine "On Pesticides and Agrochemicals", 1995; EEC Council Directive of No. 93/43, 1993).

The purpose of environmental expertise technologies of growing crops is to prevent their negative impact on the environment and human health, as well as evaluation of their environmental safety.

The main objectives of environmental expertise crop growing technologies are enclosed in determining the degree of environmental risk and safety of planned technological operations, organization of a comprehensive, scientifically based evaluation, establish consistency on the soil, quality of products, processes occurring in the components of ecological, sanitary, agrochemical and other agro-ecosystems standards, training objective, well-grounded conclusions environmental expertise (Troll, 2001; Vegetable, 2001).

The objects of environmental expertise technologies of crop growing are materials, documentation and research reports on their impact on soil fertility indicators, phytosanitary condition of crops, quality products, migration of chemicals, biological activity of soil productivity agricultural crops and economic performance. For environmental expertise should be used wool results of studies conducted over 2 years (Law of Ukraine "On Pesticides and Agrochemicals", 1995).

Environmental expertise appropriate to the system of indicators and standards that take into account the impact of technology on ecotoxicological, agrochemical, hydrochemical agroecosystem condition, quality, crop productivity.

Within certain parameters necessary to evaluate technologies for 4 classes (according to recommendations of international organizations). The range of parameters within classes defined by standards, quantitative parameters are set by adapting existing standards with regard to classical ecological approaches to environmental regulation (Troll, 2001).

If environmental regulation is assumed that deviations from the standard less than $10 \%$ - the lowest hazard level, $10-25 \%$ - moderately hazard level, and more than $25 \%$ - is dangerous hazard level.

With this technology should evaluate each indicator as follows:

Class I - poor condition (deviation from the optimum toward deterioration over $25 \%$ ).

Class II - satisfactory (deviations from the optimum toward deterioration over $10 \%$ but not exceeding $25 \%$ ).

Class III - normal (deviations from the optimum toward deterioration does not exceed $10 \%$ ).

Class IV - optimum condition (deviation from the optimum toward deterioration was observed). 
The system of indicators and standards developed by taking into account the peculiarities of growth and physiology of a particular crop.

Structure parameters for the environmental expertise technologies of crop growing:

Soil fertility (deviation from the optimal level for the content of humus, mobile forms of nitrogen, phosphorus, potassium, soil acidity etc.).

Phytosanitary status (level of weed-infested, disease, pests injuring, deviation from normal level).

Pollutants accumulation in the upper layers of soil (heavy metals, residual pesticides, radionuclides etc.).

Chemicals migration (concentration ratio in different genetic horizons of soil pollutants) (heavy metals, residual pesticides, radionuclides etc.) and nutrients (nitrogen compounds, phosphorus, potassium), speed of vertical migration of chemicals from the soil profile.

Biological soil activity (changes in the biochemical processes of soil in the structural and microbiota's functional components, deviation from the optimum condition).

Quality and product safety (compliance with standards for biochemical, technological and hygienic quality indicators).

Capacity (deviation from the optimum performance level for a given climatic zone).

Economic efficiency (performance cost, profitability etc.)
The procedure for environmental impact expertise involves checking for completeness and required materials (preparatory phase); analyzing material environmental review, full-scale survey and conduct on the basis of comparative analysis, if necessary, and partial estimates the degree of environmental safety, adequacy and effectiveness of environmental studies (main stage); summarize some expert studies, information obtained and the effects of technology, training environmental expertise report and submit it to interested agencies and entities (final stage) (EEC Council Directive of No. 93/43, 1993).

During the environmental expertise crop growing technologies in the first stage should be identified technological operations, which can cause deterioration of the environment and product quality. An example of such work to score technological operations of wheat (table 1).

At the final stage of environmental assessment is preparing a conclusion that includes a generalized assessment of technologies and separate processes, observations and suggestions for improvement and study its environmental impact, conclusions concerning approval, return for revision or rejection of its future ecological and expert review with reference to the relevant regulations, decisions on the possibility of making a decision on further implementation of technology in agricultural production.

Table 1.

Technological operations and possible negative impacts on agro-ecosystem when growing agricultural crops

\begin{tabular}{|c|c|c|}
\hline Process operation & Possible adverse effects on components of agro-ecosystem & Possible environmental impacts \\
\hline \multicolumn{3}{|c|}{ The soil tillage system } \\
\hline plowing & $\begin{array}{l}\text { - agrophysical degradation (decrease in erosion resistance of } \\
\text { soils) }\end{array}$ & $\begin{array}{l}\text { - soil erosion, } \\
\text { - intensification of chemicals migration }\end{array}$ \\
\hline cultivation & - excessive spraying of the upper layer & - violation of air and water regime of soil \\
\hline rollering & - compaction of topsoil & $\begin{array}{l}\text { - change in qualitative and quantitative characteristics } \\
\text { of the soil biota }\end{array}$ \\
\hline
\end{tabular}

Fertilization system

application of - revenues biochemically into the agro-ecosystem, active and - change in qualitative and quantitative characteristics fertilizers and hazardous pedochemicals (heavy metals, radionuclides, meliorants fluorine, etc.) of the biota of the soil,

acidification of soil solution, effects on soil biota, change production,

plant nutrition conditions $\quad$ - activation of the horizontal and vertical migration of chemicals

The crop protection system

application of - revenues highly chemical into the agro-ecosystem

- contamination of soil xenobiotics,

pesticides

- impact on the biota of the soil,

- activation switch in plants harmful substances capable of accumulation and migration by trophic chains

- deterioration of the hygienic quality of agricultural products

\section{REFERENCES}

Law of Ukraine "On Ecological Expertise" (1995): Supreme Council of Ukraine. No. 8. S. 54

Law of Ukraine "On Pesticides and Agrochemicals" (1995): Resolution of the Verkhovna Rada of Ukraine No. 87/95-VR. 16.

EEC Council Directive of 14.06.1993 № 93/43 “on the hygiene of foodstuffs" (HACCP)
Troll, M. (2001): Soils. Co. and quality of environmental and safety standards for mezhdunarodnыm. Handbook. GS Fomin. AG Fomin. Moscow. 37-41

Vegetable, K. (ed.) (2001): Quality management of crop production. 